\title{
Pulmonary reimplantation response in single-lung transplantation
}

\author{
Ch. Sleiman*, H. Mal*, M. Fournier*, J-P. Duchatelle**, P. Icard**, O. Groussard+, G. \\ Jebrak*, J-L. Mollo*, O. Raffy*, C. Roue*, M. Kitzis**, B. Andreassian+, R. Pariente*
}

Pulmonary reimplantation response in single-lung transplantation. Ch. Sleiman, H. Mal, M. Fournier, J-P. Duchatelle, P. Icard, O. Groussard, G. Jebrak, J-L. Mollo, O. Raffy, C. Roue, M. Kitzis, B. Andreassian, R. Pariente. (CERS Journals Ltd 1995.

ABSTRACT: We studied the characteristics of the pulmonary reimplantation response (PRR) in single-lung transplantation (SLT), and detailed the occurrence, evolution, prognosis and risk factors of this complication.

Forty single-lung transplant recipients were studied. Twenty four patients developed hypoxaemia and allograft infiltrates consistent with the PRR.

In $40 \%$ of the cases hypoxaemia was severe, precluding weaning and requiring prolonged mechanical ventilation with high fractional inspiratory oxygen $\left(\mathrm{FIO}_{2}\right)$. The mean duration of ventilation was 7 days (range 1-19 days). Clearing of the chest radiographs was progressive, with complete resolution between 6 and 21 days. In all cases, the pulmonary arterial wedge pressure was normal $(6 \pm 2 \mathrm{mmHg})$ suggesting low pressure oedema. Sampling of the pulmonary oedema fluid revealed that the ratio of protein concentration in oedema fluid to that in serum exceeded 0.5 . In patients with severe PRR (40\% of cases) clinical, radiographic and haemodynamic abnormalities were identical to adult respiratory distress syndrome (ARDS), but the prognosis was more favourable with no death directly related to PRR in our patients. The mean duration of graft ischaemia of the oedematous grafts (241 $\pm 103 \mathrm{~min})$ was significantly longer than that of nonoedematous grafts $(155 \pm 71 \mathrm{~min})$.

These date suggest that prolongation of graft ischaemia increased the incidence of PRR.

Eur Respir J., 1995, 8, 5-9.

Lung transplantation has become accepted worldwide as a successful therapy for patients with end-stage pulmonary disease refractory to other forms of medical treatment. Despite the improvement of the survival rate in these patients, there still exist some complications in the early postoperative period, which are the source of morbidity. The occurrence of a radiological pattern of pulmonary oedema without evidence of infection or rejection is one of these complications. This phenomenon, called pulmonary reimplantation response (PRR), was an early experience in human heart-lung transplantation [1], and is generally considered to be related to ischaemia-reperfusion lung injury. PRR has been widely studied in animal models [2-7], but few data are available in clinical lung transplantation [8-10]. The aim of this report is to describe the characteristics of PRR in single-lung transplantation (SLT), and to detail the occurrence, evolution, prognosis and risk factors of this complication.

\section{Patients and methods}

\section{Patients}

Forty patients (mean age $50 \pm 5$ yrs; 31 males and 9 females) underwent SLT in our institution from March
*Service de Pneumologie et Réanimation, INSERM U226, Hôpital Beaujon, Clichy, France. **Service de Chirurgie Thoracique, and + Service d'Anatomo-Pathologie, Hôpital Beaujon, Clichy, France.

Correspondence: Ch. Sleiman Service de Pneumologie et Réanimation Hôpital Beaujon 100 boulevard du Général Leclerc 92118 Clichy

France

Keywords: Ischaemia-reperfusion injury pulmonary reimplantation oedema pulmonary vascular permeability single-lung transplantation

Received: February 81994

Accepted after revision November 191994
1988 to January 1992 . The original diagnoses are shown in table 1.

\section{Donor selection}

Donor and recipient matching was based on size, $\mathrm{ABO}$ compatibility and cytomegalovirus status. A clear chest roentgenogram and adequate gas exchange of the donors was also required. Gas exchange was judged adequate if arterial oxygen tension was greater than $47 \mathrm{kPa}$ on $100 \%$ oxygen. In addition, arterial blood gases and a chest radiograph performed within $2 \mathrm{~h}$ of organ harvesting

Table 1. - Indication for transplantation in the 40 patients studied

\begin{tabular}{lc}
\hline Indication & $\mathrm{n}$ \\
\hline Idiopathic emphysema & 15 \\
$\alpha_{1}$-antitrypsin deficiency & 12 \\
Idiopathic pulmonary fibrosis & 5 \\
Eosinophilic granuloma & 3 \\
Pulmonary hypertension & 3 \\
Lymphangiomyomatosis & 1 \\
Bronchiolitis & 1 \\
\hline
\end{tabular}


was also required, to ensure that a new abnormality was not overlooked. The donor pool included 30 male and 10 female donors, with a mean age of $30 \pm 11$ years. Twelve donors died of subarachnoid haemorrhage, 20 donors died following motor vehicle accidents, and 8 deaths resulted from self-inflicted gunshot wounds to the head. Donors were free of chest trauma, and systemic or pulmonary infection, with normal bronchoscopic examination and minimal pulmonary secretions. The donors were aggressively managed with arterial line, central venous line, judicious fluid balance to avoid hyperhydratation, and careful pulmonary toilet. The graft was procured from 12 donors in our hospital, and 28 other donors at a distance. There was no problem in transport or handling of the grafts.

\section{Organ preservation}

Steroid therapy was not given to the donor prior to organ harvesting. Donor lung preservation was achieved with topical cooling in the first nine SLT using Eurocollin's solution. In the last $31 \mathrm{SLT}$, the single-flush technique was used: prostaglandin E1 (PGE1) was administered via a central venous catheter beginning $15 \mathrm{~min}$ before aortic cross-clamping, using $10 \mathrm{ng} \cdot \mathrm{kg}^{-1} \cdot \mathrm{min}$ of PGE1, and was gradually increased according to blood pressure tolerance to a maximum dose of $80 \mathrm{ng} \cdot \mathrm{kg}^{-1} \cdot \mathrm{min}$. PGE1 perfusion was then continued during administration of the pulmonary cooling solution. Lung perfusion cooling was performed with Euro-collin's solution cooled to $4^{\circ} \mathrm{C}$. This solution was delivered into the main pulmonary artery during $4 \mathrm{~min}$ to a total volume of $50 \mathrm{ml} \cdot \mathrm{kg}^{-1}$. The pulmonary artery pressure was not monitored during the flush technique, but the duration of perfusion and the gravitational pressure of infusion were identical in all procedures. This flush solution was drained through an incision in the left auricle. Ventilation of the donor continued during lung perfusion. After this procedure, the graft was excised and stored in a sterile plastic bag filled with Euro-collin's solution at $4^{\circ} \mathrm{C}$.

\section{Lung transplantation}

The surgical procedure was performed using a classic technique [11], without cardiopulmonary bypass. The lung was not preserved with local cooling during the transplantation procedure and no further flush solution was applied. Arterial and venous pressure, cardiac output and arterial blood gases were closely monitored during the surgical procedure. Intravenous fluid restriction was maintained peri- and postoperatively to avoid hyperhydratation, and potent diuretics were administered in an attempt to enhance urine flow.

\section{Immunosuppression}

Intravenous methylprednisolone $(500 \mathrm{mg})$ and azathioprine $\left(2.5 \mathrm{mg} \cdot \mathrm{kg}^{-1}\right)$ were administered preoperatively. Postoperative immunosuppression consisted of cyclosporin, azathioprine and antithymocyte globulin. Cyclosporin was given intravenously in the first postoperative week, the first dose being given $3 \mathrm{~h}$ after the surgical procedure. The dosage of cyclosporin was adjusted to produce a trough level of 200-300 ng. $\mathrm{ml}^{-1}$ as measured by radioimmunoassay of whole-blood samples. This level of cyclosporin was reached in all patients in the first $36 \mathrm{~h}$, and was maintained at this level until the second postoperative month. Azathioprine was given in a daily dose of $2-2.5 \mathrm{mg} \cdot \mathrm{kg}^{-1}$. Antithymocyte globulin was administered for 14 days in the first six patients, but was reduced to 3 days in the other patients. A further $500 \mathrm{mg}$ of methylprednisolone was given on the first postoperative day. Oral corticosteroids were withheld until 3 weeks postoperatively.

\section{Haemodynamic monitoring}

During the first postoperative week, all the patients had radial artery and pulmonary artery catheters for respiratory and haemodynamic management. Mean pulmonary artery pressure, mean pulmonary capillary wedge pressure and cardiac output were monitored. Arterial blood samples were drawn for blood gas analysis several times daily.

\section{Oedema fluid sampling}

Samples of blood and oedema fluid were simultaneously obtained $2 \mathrm{~h}$ after the occurrence of PRR in five patients, and were analysed for protein content. The oedema fluid was obtained by aspiration of tracheal content through the endotracheal tube.

\section{Identification of PRR}

PRR consists of a noncardiogenic oedema (wedge pressure $<12 \mathrm{mmHg}$ ), with hypoxaemia (requiring a $\mathrm{FIO}_{2}$ of $\geq 0.3$ to maintain an arterial oxygen tension $\left(\mathrm{PaO}_{2}\right)$ greater than $8 \mathrm{kPa}$ ), with alveolar and/or interstitial shadowing, occurring in the early postoperative period (within the first week) without evidence of bacterial infection or rejection.

\section{Surveillance and diagnosis of infection}

Bronchoscopy was repeated every other day in the first postoperative week, in order to obtain specimens for culture as well as to help in the clearance of the airways. Three blood cultures were performed daily in the same period.

\section{Identification of risk factors}

The following potential risk factors of PRR were evaluated: method of lung preservation (topical cooling versus the flush technique), graft ischaemic time (measured 
as the time of organ harvesting to the time of reperfusion after implantation), duration of ventilation of the donors and the $\mathrm{PaO}_{2}$ of the donors on $\mathrm{FIO}_{2} 1$.

\section{Statistics}

All measurements are expressed as the mean value \pm standard error. Paired t-tests were used. Statistical significance was taken as $\mathrm{p}<0.005$.

\section{Results}

PRR was observed in 24 cases $(60 \%$ of transplant recipients). The oedema occurred within $3 \mathrm{~h}$ of operation in 12 patients ( $50 \%$ of cases). In two of these, oedema fluid was present in the endotracheal tube within the hour following the revascularization of the graft. In five patients (20\% of cases), PRR occurred 3-12 h after transplantation, and in seven patients ( $30 \%$ of cases) it occurred a few days ( $1-4$ days) later.

In $60 \%$ of oedematous patients, hypoxaemia was moderate $\left(\mathrm{PaO}_{2} 6.6 \pm 1.3 \mathrm{kPa}\right.$ whilst breathing room air through a T-piece). Weaning of these patients was carried out between Day 1 and Day 4 after transplantation with supplemental nasal oxygen $\left(1-5 l \cdot \mathrm{min}^{-1}\right)$. In $40 \%$ of the cases, hypoxaemia was severe $\left(\mathrm{PaO}_{2}<6.6 \mathrm{kPa}\right.$ on $\left.\mathrm{FiO}_{2} 0.6\right)$, precluding weaning and requiring prolonged mechanical ventilation with high $\mathrm{FIO}_{2}\left(\mathrm{FIO}_{2}>0.6\right)$. In our oedematous patients, the mean duration of mechanical ventilation was 7 days, ranging 1-19 days. Chest radiographs showed a pattern of pulmonary oedema with alveolar and/or interstitial shadowing in the transplanted lung. Total consolidation of the lung was seen in 11 cases. Clearing of the PRR was progressive, with complete resolution between the 6th and 21 st day. In all cases, the pulmonary arterial wedge pressure was normal $(6 \pm 2$ $\mathrm{mmHg}$ ) suggesting low pressure oedema. The cardiac index was slightly diminished in nine patients $(2.6 \pm 0.2$ $l \cdot \mathrm{min}^{-1} \cdot \mathrm{m}^{-2}$ ), who developed haemodynamic profile similar to that observed in the late phase of septic shock with severe systemic hypotension $[12,13]$. In the remaining 15 oedematous patients the cardiac index was normal $\left(4 \pm 0.5 l \cdot \mathrm{min}^{-1} \cdot \mathrm{m}^{-2}\right)$ and the mean pulmonary artery pressure was $25 \pm 4 \mathrm{mmHg}$. Sampling of the pulmonary oedema fluid through the endotracheal tube in five patients, revealed that the ratio of protein concentration in oedema fluid to that in serum exceeded 0.5 , and the absolute value of protein in the oedema fluid was $>5.0 \mathrm{~g} \cdot \mathrm{dl}^{-1}$.

Immunosuppression regimen and fluid balance did not differ between oedematous and nonoedematous patients at the onset of PRR. In patients who developed PRR after $3 \mathrm{~h}$ of transplantation, cyclosporin levels were comparable to those observed in nonoedematous patients.

The mean total graft ischaemic time for the 40 SLT was $215 \pm 105 \mathrm{~min}$ (mean warm ischaemic time $=40 \pm 10$ $\mathrm{min}$ ). Prolongation of graft ischaemia increased the incidence of PRR, since the mean duration of graft ischaemia of the oedematous grafts $(241 \pm 103 \mathrm{~min})$ was significantly longer $(p=0.005)$ than that of the nonoedematous grafts

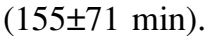

Table 2. - Correlation between the occurrence of PRR and the mean graft ischaemic time, $\mathrm{PaO}_{2}$ and the duration of ventilation of the donors

\begin{tabular}{lcccl}
\hline & & & & \\
& & & \\
& & & \\
& & & \\
Graft ischaemic time & $\min$ & $241 \pm 103$ & $155 \pm 71$ & 0.005 \\
Donor $\mathrm{PaO}_{2}$ on $\mathrm{FIO}_{2} 1$ & $\mathrm{kPa}$ & 61 & 56 & 0.5 \\
Duration of donor & 29 & 39 & 0.6 \\
$\quad$ ventilation h & & & \\
\hline
\end{tabular}

Mean values \pm SEM. PRR: pulmonary reimplantation response; $\mathrm{PaO}_{2}$ : arterial oxygen tension; $\mathrm{FIO}_{2}$ : fractional inspiratory oxygen.

In our patients, the simple hypothermic atelectasis technique was used in the first nine SLT and the single-flush technique with Euro-collin's solution in the last 31 SLT. We did not observe any difference in the occurrence of PRR in these two groups (56 and $61 \%$, respectively).

Mean duration of ventilation of the donors was $27 \pm 13 \mathrm{~h}$. All donors had acceptable gas exchange immediately before harvesting, with a mean $\mathrm{PaO}_{2}$ of $59 \pm 9 \mathrm{kPa}$ on $100 \%$ oxygen. No relationship was found between the occurrence of PRR and the duration of ventilation of the donors, as shown in table 2. Similarly, no relationship was found between the $\mathrm{PaO}_{2}$ of the donors on $\mathrm{FIO}_{2} 1$ and the incidence of PRR (table 2). No death was directly related to PRR in these patients.

\section{Discussion}

PRR consists of an oedema which occurs in the early postoperative period. This response has been widely studied in animal models [2-5], but few data are available in clinical lung transplantation [8-10, 14].

PRR was frequently observed in our SLT patients. In the early postoperative period, the differentiation of PRR due to infection or to acute rejection may be difficult because the clinical and radiographic abnormalities of these complications are similar, and PRR is usually diagnosed by exclusion. Our patients were free of bacterial infection when PRR occurred, and allograft rejection rarely occurs during the first few days after transplantation. We did not perform transbronchial biopsies to rule out this diagnosis, but in patients who developed PRR after the third postoperative day, administration of methylprednisolone $\left(1 \mathrm{gm} \cdot \mathrm{day}^{-1}\right.$ for 3 days $)$ did not improve the clinical situation.

Excessive fluid administration in the donors or the recipients could be proposed as a possible aetiology of PRR. However, our donors were free of pulmonary oedema, and had normal blood gases and clear chest roentgenograms before lung harvesting. Furthermore, the fluid balance was critically controlled during the perioperative and postoperative periods in the recipients, and the presence of a normal or low pulmonary arterial wedge pressure among our patients provides strong evidence that endothelial damage and increased permeability were the cause of the oedema.

Since the graft receives the majority of the cardiac output because of lower vascular resistance than in the native lung $[15,16]$, we could suspect the role of overperfusion 
of the transplanted lung as a possible aetiology of PRR. It seems unlikely, because this phenomenon results only from hydrostatic oedema with high wedge pressure. Thus, PRR seems to be a membrane permeability oedema. In $40 \%$ of oedema cases, the clinical feature was that of an adult respiratory distress syndrome (ARDS), requiring prolonged mechanical ventilation with high $\mathrm{FIO}_{2}$ and delaying the withdrawal of mechanical ventilatory support after transplantation. This prolonged mechanical ventilation can be a source of morbidity, such as nosocomial bacterial pneumonia or barotrauma. In contrast with what is observed in ARDS, the addition of a positive end-expiratory pressure to allow a decrease of the $\mathrm{FIO}_{2}$ below the toxic range was rarely successful in our patients with PRR. This finding could be explained by the fact that PRR was unilateral, involving the transplanted lung only. Nevertheless, the pathogenesis of this phenomenon is still an unsolved problem.

The oedema is probably due to an increase in microvascular permeability, which could be related to ischaemiareperfusion lung injury. In animal models, it has been demonstrated that pulmonary oedema was related to ischaemia-reperfusion injury of the graft $[3,4,17]$. Among the possible mechanisms, there is a growing body of evidence that reactive oxygen metabolites are a fundamental mechanism of tissue injury during reperfusion of ischaemic skin, intestine, liver, kidney, myocardium, and lung [18-25]. Oxygen free radical scavengers, such as superoxide dismutase, catalase and dimethylthiourea, have been shown to attenuate ischaemia-reperfusion injury in several animal studies [26-30], but have not been applied clinically. The long-term preservation of the lung grafts still lags behind the preservation of other organs for transplantation, and the uncertainty of the optimal method of lung preservation has resulted in the application of many techniques of preservation for lung transplantation. However, many experimental studies have demonstrated the superiority of extracellular fluid solutions over Euro-collin's solution for pulmonary preservation [31-33]. In our patients, we found a correlation between the duration of the graft ischaemia and the occurrence of PRR. This correlation was also found in animal models [3], in which prolongation of graft ischaemia increases the incidence of obvious oedema formation. KAPLAN et al. [10] evaluated the pulmonary vascular permeability in 15 patients after lung transplantation by measuring a quantitative index of vascular permeability, and they found that the longer preservation time was associated with higher index values. Curiously, BAvoux et al. [9] did not find any correlation between PRR and the graft ischaemic time in 35 heart-lung recipients [9].

However, despite the increasing evidence from human and animal models that supports the close relationship between the duration of graft ischaemia and the occurrence of PRR, we think that a short ischaemic time does not always prevent this complication. In seven patients, PRR occurred 1-4 days after transplantation. It is difficult to accept that PRR is due exclusively to reperfusion injury in these cases. However, there was no evidence of infection in these patients, and radiological signs and blood gas abnormalities did not improve after augmented immuno- suppression. Other factors, such as denervation, surgical trauma and disruption of lymphatic structures, may be considered as additional factors in the occurrence of PRR. BAvoux et al. [9] found a relationship between the $\mathrm{PaO}_{2}$ of the donors on $\mathrm{FIO}_{2} 1$ and the incidence of PRR. This relationship did not exist in our patients (table 2 ).

In conclusion, we observed that PRR is frequent after lung transplantation. Clinical, radiographic and haemodynamic abnormalities are identical to ARDS, but, in contrast to ARDS, the prognosis for patients with PRR is very favourable, with no death directly related to PRR in our patients. We think that PRR may be a form of reperfusion injury. Preservation techniques are probably important contributors to this response, therefore, improvement of the methods available seems to be indicated, and much more work needs to be performed to elucidate the "aetiology" of this phenomenon.

\section{References}

1. Reitz BA, Wallwork JL, Hunt SA, et al. Heart-lung transplantation: successful therapy for patients with pulmonary vascular disease. $N$ Engl J Med 1982; 306: 557-564.

2. Siegelman SS, Sinha SBP, Veith FJ. Pulmonary reimplantation response. Ann Surg 1973; 177: 30-36.

3. Prop J, Ehrie MG, Crapo JD, Nieuwenhuis P, Wildevuur $\mathrm{CRH}$. Reimplantation response in isografted rat lungs: analysis of causal factors. J Thorac Cardiovasc Surg 1984; 87: 702-711.

4. Paull DE, Keagy BA, Kron EJ, Wilcox BR. Reperfusion injury in the lung preserved for 24 hours. Ann Thorac Surg 1989; 47: 187-192.

5. Klausner JM, Paterson IS, Kobzik L, Valeri CR, Shepro D, Hechtman HB. Oxygen free radicals mediate ischemiainduced lung injury. Surgery 1989; 105: 192-199.

6. Su M, Chi EY, Bishop MJ, Henderson WR Jr. Lung mast cells increase in number and degranulate during pulmonary artery occlusion/reperfusion injury in dogs. Am Rev Respir Dis 1993; 147: 448-456.

7. Seibert AF, Haynes J, Taylor A. Ischemia-reperfusion injury in the isolated rat lung. Am Rev Respir Dis 1993; 147: 270-275.

8. Veith FJ, Koerner SK. The present status of lung transplantation. Arch Surg 1974; 109: 734-740.

9. Bavoux E, Cerrina J, Lafont D, et al. Oedemes pulmonaires de reimplantation après transplantation cardiopulmonaire (Abstract). Réan Soins Intens Méd Urg 1990; 6: 057.

10. Kaplan JD, Trulock EP, Cooper JD, Schuster DP. Pulmonary vascular permeability after lung transplantation. $\mathrm{Am}$ Rev Respir Dis 1992; 145: 954-957.

11. Cooper JD, Pearson FG, Patterson GA, et al. Technique of successful lung transplantation. J Thorac Cardiovasc Surg 1987; 93: 173-181.

12. Mal H, Sleiman Ch, Jebrak G, et al. Early hemodynamic complications after lung transplantation (Abstract). Am Rev Respir Dis 1992; 145: A702.

13. Mal H, Dehoux M, Sleiman Ch, et al. Role of tumor necrosis factor in the pathogenesis of early systemic hypotension after lung transplantation (Abstract). Am Rev Respir Dis 1993; 147: A602.

14. Herman SJ. Radiologic assessment after lung transplantation. Clin Chest Med 1990; 11: 333-346. 
15. Mal H, Andreassian B, Pamela F, et al. Unilateral lung transplantation in end-stage pulmonary emphysema. Am Rev Respir Dis 1989; 140: 797-802.

16. Sleiman Ch, Mal H, Andreassian B, Pariente R. Singlelung transplantation in pulmonary emphysema. $N$ Engl J Med 1990; 323: 551.

17. Alican F, Cayirli M, Isin E, Hardy JD. Surgical technique of one-stage bilateral lung reimplantation in the dog. J Thorac Cardiovasc Surg 1971; 61: 847-856.

18. Nordstrom G, Seeman T, Hasselgren PO. Beneficial effect of allopurinol in liver ischemia. Surgery 1985; 97: 679-683.

19. Parks DA, Bulkley GB, Granger DN. Role of oxygenderived free radicals in digestive tract diseases. Surgery 1983; 94: 415-422.

20. Ratych RE, Chuknyiska RS, Bulkley. The primary localization of free radical generation after anoxia/reoxygenation in isolated endothelial cells. Surgery 1987; 102: 122-131.

21. Stewart JR, Crute SL, Loughlin V, Hess ML, Greenfield LJ. Prevention of free radical-induced myocardial reperfusion injury with allopurinol. J Thorac Cardiovasc Surg 1985; 90: 68-72.

22. Horgan MJ, Lum H, Malik AB. Pulmonary edema after pulmonary artery occlusion and reperfusion. Am Rev Respir Dis 1989; 140: 1421-1428.

23. McCord JM. Oxygen-derived free radicals in postischemic tissue injury. N Engl J Med 1985; 312: 159-163.

24. Linas SL, Whittenberg D, Repine JE. Role of xanthine oxidase in ischemia/reperfusion injury. Am J Physiol 1990; 258: 711-716.
25. Weiss SJ. Tissue destruction by neutrophils. $N$ Engl $J$ Med 1989; 320: 365-376.

26. Fox RB. Prevention of granulocyte-mediated oxidant lung injury in rats by a hydroxyl radical scavenger, dimethylthiourea. J Clin Invest 184; 74: 1456-1464.

27. Zimmerman JJ. Therapeutic application of oxygen radical scavengers. Chest 1991; 100: 189-192.

28. Cremer J, Jurmann M, Dammenhayn L, et al. Oxygen free radical scavengers to prevent pulmonary reperfusion injury after heart-lung transplantation. J Heart Transplant 1989; 8: 330.

29. Lambert CJ, Egan TM, Detterbeck FC, Keagy BA, Wilcox BR. Enhanced pulmonary function using dimethylthiourea for twelve hour lung transplantation. Ann Thorac Surg 1991; 51: 924.

30. Detterbeck FC, Keagy BA, Paull DE, Wilcox BR. Oxygen free radical scavengers decrease reperfusion injury in lung transplantation. Ann Thorac Surg 1990; 50: 204210.

31. Yamazaki F, Yokomise H, Keshavjee SH, et al. The superiority of an extracellular fluid solution over Eurocollin's solution for pulmonary preservation. Transplantation 1990; 49: 690-694.

32. Fujimara S, Handa M, Kondo T, Ichinose T, Shiraishi Y, Nakada T. Successful 48 hour simple hypothermic preservation of canine lung transplants. Transplant Proc 1987; 19: 1334-1336.

33. Keshavjee SH, Yamazake F, Yokomise H, et al. The role of dextran 40 and potassium in extended hypothermic lung preservation for transplantation. J Thorac Cardiovasc Surg 1992; 103: 314-325. 